\title{
Cristo más allá del dogma. Hacer cristología en el contexto de las religiones de los pobres ${ }^{1}(\mathbf{I})$
}

\author{
Aloysius Pieris, S. J. \\ Tulana Research Centre \\ Gonawala-Kelaniya \\ Sri Lanka
}

\section{Primera parte \\ El arte de formular nuestra agenda teológica}

\section{El dogma y el sutra}

En la tradición cultural índica existen sutras y no existen dogmas, tal como se los entiende en la teología cristiana contemporánea. Desde el principio es importante hacer notar la diferencia entre ambas cosas y caer en la cuenta de sus implicaciones, pues bien pudiera suceder que tengamos que abandonar el camino que llevó a la formulación de los dogmas cristológicos y tengamos que recorrer un camino altemativo si es que queremos comprender y expresar el misterio de la redención, con la mirada puesta en el calvario, donde, sub Pontio Pilato, en circunstancias políticas registradas históricamente, Jesús se reveló a sí mismo

1. Lo que vamos a proponer en este articulo supone el cambio de paradigma que ya sugcri en God's Reign for God's Poor. Return to the Jesus Formula (Kelaniya, Sri lanka, 1999). El texto fue entregado a los participantes del Congreso Ecuménico de Jesuitas (Kollayam, India, agosto, 1999), en el cual fue leída la primera redacción del prescnic arlículo.

2. Uso la palabra "índica" para designar el vasto campo cultural que se extiende mucho más allá del territorio polílico, unificado como "India" bajo la administración colonial británica, y que quedó despućs dividido, formando Pakistán un estado scparado. El elemento índico no se reduce a lo indio. Mucho antes de que se formase el Estado de la India, compuesto por una gran parte de la región indica, ya existía un bueno grupo de regiones con una tradición cultural índica. 
como el Cristo, el mesías, el liberador, en el contexto de un conflicto social, de una confrontación pública entre el mundo que él había soñado y el que nosotros hemos construido. Pues bien, la noción de dogma, hoy en boga, impide este cambio crucial de énfasis en la manera de hacer cristología.

El significado de la palabra griega "dogma", tal como ha sido aceplado en la teología cristiana tradicional, no se puede remontar a la Escritura. En la Sepluaginta y en el Nuevo Testamento, "dogma" significa decreto u ordenanza, sea del Estado (Dan 2, 15; 3, 10; Lc 2, 1; etc,), sea de la comunidad de los creyentes, como, por ejemplo, las órdenes que da Moisés ( $\mathrm{E}[2,15$; Col 2,14) o las normas práclicas que adoplaron los apóstoles (ta dogmata ta krekrimena upo ton apostolon), en el concilio de Jerusalén (Hech 16, 4). Obviamente, este significado era aceptado en el mundo griego.

En la literatura griega clásica, la palabra "dogma" significaba también una opinión o una doctrina autorizada e incuestionada por provenir de algún reconocido filósofo. Este significado específico del término es el que quedó asentado en el vocabulario eclesiástico en forma masiva. Denota una verdad revelada, consignada en una tradición escrila y, o no escrita; una verdad, por tanto, definida, es decir, formulada por la autoridad legílima ( $y$, después, infalible) de la Iglesia lo más exactamente posible para excluir así cualquier apariencia de error, y convertirse en formulación obligante para la fe. Por esa razón, su negación es considerada, como negación de la ortodoxia de una persona. Pero esta noción de "dogma" —repitámoslo- no encuentra ningún apoyo en las Escrituras.

La declaración de dogmas comenzó como reacción a desviaciones doctrinales, lo cual, a su vez, surgió de la tendencia eclesial a "doctrinizar" el contenido de la revelación. Este recordatorio es importante, porque la necesidad de formular un dato de la fe en forma de doctrina y en lenguaje inequívoco parece que ha ido aumentando a lo largo de los años. Estas formulaciones que, lécnicamente, llegaron a convertirse en definiciones, tolerarán algún tipo de ambigüedad sólo cuando algún aspecto del dato revelado no es absolutamente claro para quienes lo definen. De no ser así, lales formulae asegurarán la precisión, especialmente cuando la herejía concreta, que movió a formular las definiciones, ya había expresado los límites exaclos entre verdad y crror. Esto es totalmente legílimo, y aun necesario, para cualquier comunidad de fe. De hecho, la lglesia universal ha quedado agradecida a los obispos y leólogos que desarrollaron esta Iradición.

Dicho esto, no podemos dejar de expresar reservas sobre una cierta limitación cultural que ha afectado a la comprensión tradicional de la finalidad y la naturaleza de los dogmas así definidos. Me refiero al cambio juridicista que sufrieron tales formulaciones doctrinales debido a la orientación hacia la jurisprudencia en el modo romano de gobernar, legado que la Iglesia heredó del imperio. Walter Ullman ha señalado que, bajo la influencia de juristas como Tertuliano, en la Iglesia latina apareció la tendencia a formular sentencias y 
principios "religiosos" como sentencias y principios jurídicos". Así, el concepto de "canon" como regla de fe acordada, el concepto de culto, de comporlamiento y de gobierno, tendieron a asumir una rigidez legalista que, quizás, no era necesaria para mantener la comunión en la fe. ¿No refleja la tendencia de los grandes concilios a recurrir a "cánones" - a los que les sigue el anathema sit- esa orientación juridicista?

Como lo ha hecho nolar David Paul, el surgimiento de normas autorilativas, tales como la constitución del texto sagrado (canon de la Escritura), de la regla de fe (credos), de la ordenación del culto (liturgia) y de un modo establecido de gobierno (episcopado), conllevaba un gran riesgo: "surgió la lentación de identificar estas mediaciones con la auloridad y el poder divino a cuyo servicio eslaban" ${ }^{\prime 4}$. La Iglesia, cierlamenle, sucumbió a este peligro. Las formulaciones de le, cuyos contomos conceptuales comenzaron a configurase cada vez más en una interminable serie de debates, dejaron de ser meras mediaciones de autoridad y se convirtieron en dogmas, que usurparon el status de auloridad de la misma revelación divina.

En este contexto, las doctrinas que llegaron a ser definidas como dogmas asumieron un carácter disciplinariamente prescriptivo, más que pedagógicamente descriptivo; un carácter definitivo e irreformable, más que evocativo e inspirador. La fe personal, es decir, la aclitud más intima del creyente hacia su Señor y Salvador en lo más profundo de su ser, comenzó a ser objeto de juicio - y quienes se desviaban eran condenados- sobre la única base de su adhesión a la fórmula de fe, lo cual, obviamente, presuponía la reverente sumisión a (el juicio de) aquellos que crearon la fórmula.

Con el decurrir del tiempo, la auloridad de la fórmula coincidió con la autoridad que tenia el formulador-promulgador, sin poder distinguir ya entre ambas cosas. Fue una especie de anticipación, en la esfera doclrinal, de lo que, después, John Hobbes aplicaría a la esfera legal: auctoritas non veritas facit legen (la auloridad, no la verdad, determina qué es ley). El Vaticano II trajo alguna esperanza. Y así, por lo que toca a la recepción de un documento promulgado por el magisterio, el concilio, como bien lo captó Yves Congar, desplazó sabiamente la fuente de autoridad a la naturaleza obligante del documento en sí mismos. Pero esta postura

3. Véase Walter Ullmann, A History of Political Thougth: The Middle Ages, Penguin Revised Edition (Middlesex, 1970), pp. 20-21 y passim.

4. David Power, "Power and Authorily in the Early Christian Cenlurics", en Michacl Downey (ed.), That They Might Live: Power, Empowerement and Leadershnip in the Church, Crossroad (New York, 1991), p. 28.

5. Yves Congar, "A Bricf History of the Forms of the Magistcrium and Its Relation with Scholars", The Magisterium, p. 326, citado en James F. Keenan, S. J., "CompeIling Assent: Magisterium, Conscience and Oaths", The Irish Theological Quarterly, vol 57, n. 3 (1991), pp. 215-216. 
conciliar no ha tenido la fuerza suficiente para que el actual magisterio se acomode a ella.

De ahí que la comprensión que se tiene, en la actualidad, de ortodoxia doctrinal presupone un aparato institucional que puede detectar y descifrar lo íntimo de la fe de una persona a través de un canon de fe, expresudo con precisión conceptual, que se asemeja a un código jurídico ante un tribunal. Cuando la verdad salvílica, una Persona Viviente que desencadena la fe del creyente, se "doctriniza" gradualmente y queda fijada en proposiciones, entonces él assensus intellectus ("asentimiento intelectual") a esa verdad formulada —exactamente así llegó a ser comprendida la fe en el pensamiento escolástico- parece necesitar un sistema de monitoreo igualmente eficaz, que mantenga la pureza doctrinal. Este sistema doctrinal consiste, comprensiblemente, en una poderosa clase clerical, equipada con masivos poderes punitivos, como lo ha lamentado el eclesiólogo e historiador de la Iglesia Giuseppe Alberigo".

Según esto, ¿podrá sorprender que los dogmas, pensados para asegurar la unidad en la koinonia cristiana, terminaran destruyéndola? Como es bien sabido, la historia de los dogmas cristológicos no es una historia edificante de un desarollo inocuo de la doctrina. Es más bien, una triste historia de graves incomprensiones, acompañada de intrigas políticas y de violencia física ${ }^{7}$. Como todos sabemos, el concilio de Calcedonia, en el año 451, condenó al patriarca de Alejandría e incluso lo depuso de su sede por supuesto monofisitismo. Quince siglos más tarde la sede de Roma se vio obligada a revocar la condena en una encíclica (Sempiternus Rex Christus, septiembre de 1951), iexplicando que la incomprensión fue debida a un vocabulario confuso! Una fórmula no puede sustituir al espíritu de Cristo como principio que garantiza la koinonia en la fe.

En la actualidad, la posibilidad del desarrollo de los contenidos de un dogma se admile en principio, al menos desde Newman, e incluso la noción de una "jerarquía de verdades" (algunas de ellas consideradas como centrales y otras como periféricas) está afectando nuestra aclual comprensión de "verdades definidas". De ahí que sea posible admilir, en principio, que un dogma, en cuanto es un construclo humano, es una expresión de fe relativa (es decir, no absolula), condicionada a una época y limilada culturalmente. La lórmula, por lo tanto, no debería ser usada como norma absoluta para medir la ortodoxia. Esta postura sensata y razonable es la que los "absolutistas" del patriarcado occidental han

6. Giucseppe Alberigo, "Communione c vcrila", cn Albcrlo Mclloni y Gianni La Bclla (cds.), L'Alterita: Concezioni ed experienze nel cristianesimo contemporanco (Bologna, 1996), pp. 237-254.

7. Cfr. Andrew Hamilion, "Crecds as Anli-personal Lincs". Pacifica 11/1 (1998), pp. 27-5.3.

8. Vaticano II, Unitatis Redimegrasion. N. II. 
condenado como "relativismo", acusación que se ha dirigido contra teólogos asiáticos, especialmente de India. Estemos, pues, de acuerdo en que la intención primaria de un dogma es servir a la comunidad creyente como guía segura y ayuda práctica para promover y hacer fructificar nuestra fe y esperanza, en un Dios que es amor.

Si se acepta lo que acabamos de decir, entonces estamos muy cerca de la noción de surra, por la que abogamos ardientemente como un posible modelo para "formular una verdad salvífica", es decir, un modo sutil y estélico de usarar palabras humanas para evocar fe, esperanza y amor. Por la misma razón, animados por nuestra confianza en la presencia del Espíritu dentro de y en medio de nosotros, nos hacemos esta pregunta crucial: ¿no seria posible comenzar a tratar todos los dogmas existentes como sutras, redimiéndolos así del tono juridicista de una cultura particular y evitando que sean usados como un aparato a control remoto, en manos de un único grupo de personas?

La literatura sutra tiene su origen en la antigua sociedad índica como instrumento práctico de resumir sus abundantes escritos con tersa claridad, a través dc un medio lingüístico que era, a la vez, mnemonómico y eufónico. Su finalidad era la de ayudar a la gente normal a recordar con facilidad verdades importantes y a reflexionar en profundidad sobre ellas. "La brevedad era el alma de este nuevo estilo literario, al punto de que hay un proverbio (tomado del Mahabhasya) que dice: "iun autor se regocija tanto en ahorrar la mitad de una vocal corta como en el nacimiento de un hijo" "w"'.

En otras palabras, la composición de un sutra exige la misma atención a la disciplina inleleclual y la precisión conceptual que la formulación de un dogma cristiano; la diferencia estriba en que los sutra-karacas nunca han reclamado inspiración divina en su recopilación"'. De ahí que los sutras no lienen el peso de sruti o revelación, pues son considerados como constructos humanos. No son, pues, exactamente dogmas en el senlido de la Iradición cristiana. Más aún, un sutra normalmente es una mezcla de exaclitud conceplual y fraseología eufónica, más evocativo, por lo tanto, que meramente declarativo. En teologia serviría para Iraer la revelación hasta la puerta de nuestra casa. por así decirlo, y esperar a que se desencadene una respuesta. No seria un instrumento de control, sino simplemente una invilación a la fe, la esperanza y el amor.

9. R. Mukcrji, Ancient Indian Education, Brahamanical and Buddhist (Delhi. 1989), pp. 162-164. Para comprender esla afirmacion hay que recordar que en la anligua sociedad brahmánica, especialmente antes de que ganase terreno la creencia en la recncarnación (como fuc lambićn cl caso cnirc los paltriarcas de Isracl. antes de que llegase a ser aceptada la creencia en la resurrecciion). el nacimiento de un hijo cra la única garantía de supervivencia después de la muerte y, por lo lanto, era la mayor fucnic de plenificación humana y gozo cspirilual.

10. Mukerji, ibid. 
Sin duda alguna, el género sutra ha servido de medio de comunicación útil en varios campos del conocimiento y de la acción en los antiguos pueblos índicos, tales como la medicina, lo jurídico, lo político, lo artístico... En el discurso teológi$c o$, en el que ahora nos movemos, nos ocupamos de sutras que expresan nuestra $f e$, que es inseparable de la esperanza, siendo ambas cosas dimensiones del amor.

Nuestra intención es desamollar, a continuación, algunos sutras que desmenuzan y explican el dato básico del cristianismo, que consiste en lo siguiente:

El amor, que es nuestra salvación, no sólo es el nombre de Dios (es decir, la realidad que la palabra "Dios" significa), sino que es también la palabra de promesa de Dios, es decir, "ama a Dios y a tu prójimo y te daré vida eterna". Esta palabra de promesa, que nos invita a expresar nuestra esperanza a través de la acción salvifica que manifiesta nuestro amor, es Jesús, quien también encama, es decir, constituye, esta acción.

La cristología que vamos a elaborar en estas páginas, a través del desarrollo progresivo de tres sutras, no es más que un comentario a esta simple afirmación.

\section{El sutra sobre "la fe que es esperanza de amor"}

Creemos que el amor es la misión de Dios —que todo lo impregna- en Cristo". La razón es que Dios, a la vez, es amor y desencadena amor. Esta fe puede muy bien ser reformulada como nuestro primer sutra:

El amor es, a la vez, el ser mismo de Dios, así como la palabra de Dios hacia nosolros. (Primera fórmula.)

"El amor" (hesed) que se predica de Dios en la Biblia lleva consigo la noción de lealtad y fidelidad (emet). Ahora bien, "fidelidad" presupone que el Dios que es amor expresa su ser Dios en una palabra que constituye una promesa. Dios es, por lo tanto, como lo sabemos por Moisés, los profetas y Jesús, un Dios hecho alianza, un Dios que se ha ligado a sí mismo a nosotros con una promesa. Cuando Dios habló, hizo realidad una promesa. En otras palabras, la palabra de Dios es esencialmente una alianza. Y esa palabra de alianza de Dios es lo que IJamamos Jesús, el Cristo. El es la promesa de Dios a nosotros, es decir, una palabra de amor (hesed) que es proferida $y$, por lo tanto, hecha real, al mantener la fidelidad de Dios (hemed). Y sólo este tipo de palabra es la que guia nuestra agenda teológica.

Desaforlunadamente, la palabra no siempre ha sido concebida en este sentido dinámico. Muy pronto se nola que existen por lo menos dos diferentes modos de concebir la palabra, que, a su vez. dan origen a dos diferentes agendas leoló-

11. Yves Congar, en Geoffrey Chapman, The Mystery of the Church (Londres, 1965), p. 106, n. 1, aprecia una correspondencia exacta entre "como el Padre me ha coviado..." (Jn 15, 19) y "como cl Padre me ha amado, así les he amado yo" (Jn 17, 23.26). 
gicas. La primera es el modelo logos, de especulación, que fue adoptado por los teólogos aceptados en la lglesia, es decir, los escolásticos en el pasado y los "curiales" y "liberales" de hoy. El segundo es el modelo dabar, de compromiso, defendido por los teólogos de la liberación de todos los continentes'2.

En nuestra agenda teológica, la palabra no es el mero logos de los filósofos estoicos (un principio racional para interpretar el mundo), sino el dabar de los profetas de Israel (una fuerza activa para cambiar el mundo). Lo que hace activa a la palabra es el aliento de vida del mismo Dios, sin el cual ninguna palabra es expirada. Y a la inversa, cuando Dios expira su Espíritu, acaece un hablar creativo. Por lo tanto, no es erróneo decir que la palabra de promesa, al quedar cumplida cuando el Cristo resucila en un cuerpo con nosolros, se convierte en el "Espíritu que da vida" (1Cor 15, 45). Esta es la razón por la cual la Palabra no puede ser reducida a un logos sin espíritu. Más bien, como lo indica Juan en el prólogo a su evangelio, la Palabra está investida de poder para ejecutar lo que expresa, pues fue a través de la palabra que todas las cosas fueron hechas (Jn 1, 3). Dijo Dios "hágase la luz" y la luz llegó a ser (Gn 1, 3). Por esa razón, creemos que la palabra de promesa de Dios lleva consigo la ejecución de su cumplimiento; que la palabra de amor (hesed) implica necesariamente lealtad (emet). Así, Jesús es la palabra de Dios a nosolros. Así también, Jesús es nuestra respuesta humana a Dios, nuestra fidelidad a Dios, nuestra alianza con Dios. Pues en él Dios nos dice "sí" a nosotros y nosotros decimos "amén" a Dios (2Cor 1, 18-22).

De todos los mandamientos de Dios se dice también que son "palabras" (debarim) dichas a nosotros. La palabra que recapitula todos los mandamientos es Jesús, pues él es también el deseo de Dios en acción y su palabra eficaz que resume todas las "palabras" reveladas a través de la ley y los profelas: ama a iu Dios y ama a ru prójimo (Mi 22, 37-40) o ama a /Dios en/ tu prójimo (Rom 13, 8-9). Esto es el todo de la revelación y de la salvación. De ahí que nuestro siguiente surra, que profundiza el conlenido cristológico del primero, puede ser formulado de la siguiente manera:

La palabra de Dios a nosotros es Jesús, desencadenando y dando cuerpo a nuestro amor a Dios y al prójimo. (Segunda fórmula.)

Cualquier cristología que no haya logrado expresar el vínculo eterno ( $i 0$ debiéramos decir identidad?) entre Jesús que es la palabra y la palabra que desencadena amor (a Dios y al prójimo), lal como se dijo en la anterior sutra, es un ejercicio vacío que nada liene que ver con la misión de Crislo, que es la salvación de todo el cosmos, a través del amor.

Al decir esto ha quedado asentado el más fundamental de los dos problemas que surgen de la doctrina cristológica elaborada por el concilio de Calcedonia, a

12. Esla idca germinal la he desarrollado en Fire and Water (Nucva York, 1996), pp. 138-146. 
saber, que, aun siendo correcla en lo que trata de decir en un lenguaje filosóficamente sofisticado, sin embargo, desafortunadamente, es irrelevante y periférica, desde el punto de vista de lo que constituye realmente la singularidad irrepetible (uniqueness) de la persona y misión de Jesús. De ahí la ironía de que un dogma que no aborda el tema fundamental de esa singularidad irrepetible de Jesús sea usado como criterio para acusar a los teólogos asiáticos de relativizar a Cristo. Este es un asunto grave, que afecta a la Iglesia universal y que, por lo tanto, debe ser discutido con mayor amplitud.

El segundo problema es que la doctrina conciliar no sólo es irrelevante, sino que es también engañosa, desde un contexto asiático. Como este segundo problema afecla sólo a las iglesias asiálicas, trataré de explicarlo lo más brevemente posible, antes de volver a la primera pregunta en la que todas las iglesias están comprometidas.

Reformulemos el segundo problema: el lenguaje de Calcedonia es tan particular y tan restringido culturalmente que no solamente es incomprensible, sine que es positivamente contraproducente en Asia, porque la traducción más fiel del concilio a muchas de las lenguas asiáticas acaba diciendo exactamente lo contrario de lo que querían decir los padres del concilio. Presenta a Cristo, en efecto, como un dios-hombre, es decir, como la encarnación de uno de los muchos "poderes cósmicos" (devas), a los cuales algunas religiones asiáticas rechazan conceder un słatus salvífico". De aquí que, en nombre de Calcedonia, hay que abandonar su propio lenguaje teológico. En esto encuentro abundante apoyo en Josef Neuner, S. J., el teólogo austríaco que ha formado a varias generaciones de sacerdotes en India y que también estuvo presente como peritus en el Vaticano II. Hablando desde el punto de vista de India, dice:

Debemos admitir que las antiguas definiciones dogmáticas cristológicas, expresadas en categorías de filosofía y antropologías griegas, no guardan relación con los marcos de pensamiento indio. En palabras de A. Pieris, "la fórmula de Calcedonia carece de senlido cuando se la traduce (si es que la Iraducción es posible) a muchas lenguas asiáticas" (Vidyajyoti Journal 1993, p. 595). El marco de trabajo antropológico es simplemente diferente ${ }^{14}$.

Desafortunadamente muchos teólogos que critican las cristologías germinales de los asiáticos lo hacen desde la mentalidad calcedoniana. Muchos de los

13. Para un análisis más detallado, véasc A. Picris, "Christology in Asia. A Reply to Felipe Gómez", en Voices from the Third World XI/2 (1989), pp. 155-172.

14. J. Neuner, "Mission Theology after Vatican II", Vidyajyoti Journal of Theological Reflection, Vol. 58, N. 4 (1994), p. 213. En cl mismo artículo también apoya mi propuesta (que explicaré en la segunda parte) de que la cristología debe ser desartollada a partir de Jos "dogmas" fundamentales, a saber, el conflicto entre Dios y Mammon y el paclo cntre Dios y los pobres en defensa de ćstos. Sin embargo, cl autor pone sobre aviso conlra una nociva inlerpretación política de estos dos principios. 
argumentos usados para defender la así llamada "singularidad irrepetible de Cristo" (una frase que desecharé después, porque no liene ningún sentido), en contra de las supuestas desviaciones de los teólogos asiáticos, están basados en un esquema de pensamiento que los asiáticos han abandonado, precisamente, por irrelevante y peligroso.

Ciertamente, hay que estar de acuerdo con lo que Calcedonia trataba de decir dentro de su propio paradigma, es decir, que lo divino y lo humano no permiten Cusión ni división, en el modo de constituir a Jesús como una unidad personal. Al reconocer esta verdad, expresamos debidamente nuestra ortodoxia y nuestra solidaridad con la fe de la Iglesia. Pero cómo - exaclamente- las dos naluralezas permanecen distinlas y a la vez unidas es una pregunta que, desde la perspectiva soteriológica, parece intranscendente y desafia toda explicación humana, y, por lo tanto no puede ser invocada como criterio de ortodoxia's. Al mismo liempo, quisiera reiterar que, al definir la unidad y la distinción enlre las dos naturalezas en una persona, el concilio de Cálcedonia no presió atención a los problemas fundamentales que implica la definición de Jesús como persona y acontecimiento irepetibles (el primer problema). Y, además, aquí en Asia, no vemos la más mínima posibilidad de proclamar al Cristo de nuestra fe, usando el modo de expresión calcedoniana (el segundo problema).

De ahí que, antes de elaborar un paradigma asiático o de argumentar en su contra, tenemos que estar de acuerdo en lo que realmente constituye la base de una auténtica cristología. El mayor obstáculo para alcanzar tal consenso es el patriarcado occidental, pues parece considerar su propia formuloción como algo absolutamente esencial en la profesión de nuestra fe porque la fórmula supuestamente define "la singularidad irrepetible de Cristo". A menos que sus teólogos progresistas se unan a los asiáticos en una renovada búsqueda de Cristo, continuará impidiendo que la tolalidad de la Iglesia se embarque en este proyecto atrevido e intrépido, lo cual debiera haber hecho hace mucho tiempo.

Esla es la razón por la cual en el presente arlículo, en el que se propone una visión común de Cristo para todas las iglesias, me abstendré de citar a un solo leólogo asiático. En su lugar, mencionaré el apoyo de investigadores occidentales clarividentes como cstrategia para mostrar que, en la aclualidad, en cristología, existe un cambio de paradigma en la lglesia universal.

Dicho esto, volvamos al primero de los dos problemas con que nos encontramos en las definiciones de Calcedonia, a saber, que las preguntas que se hizo el concilio estaban muy alejadas de la enserianza central de Jesús, en la cual se

15. Me quedé estupefaclo al enterarme (Jivan, noviembre de 1999, p. 16) de que la congregación valicana para la doctrina de la fe pidió a Jacques Dupuis que respondicse claramente a esta pregunla, siendo asi que ni él ni la congregación de la fe lo puedel hacer. 
resume la ley y los profetas, es decir, todo el ámbito de la revelación y de la salvación, lo cual, por lo tanto, no sólo constituye la misión de Cristo, sino que está personificado en Cristo, pues él es, a la vez, nuestro Dios y nuestro prójimo. Y lo importante para nuestro propósito es que, sin tener en cuenta este interés fundamental, no tiene sentido hablar de la singularidad irrepetible de Cristo. Para corregir esta laguna en la fórmula de Calcedonia he ofrecido el segundo suira, citado más aniba: "Jesús es la palabra de Dios a nosotros, desencadenando y personificando nuestro amor a Dios y al prójimo", lo que desarrollaré como el doble "dogma" cristológico (cfr. tercera parte 1).

Concedo que, prima facie, pareciera que estoy incurriendo en la crítica de un teólogo tan eminente y progresista como Karl Rahner, al tener la osadía no solamente de "dejar de lado" la pregunta suscitada y respondida por Calceldonia como de alguna forma irrelevante desde la perspectiva de la persona y misión de Cristo, sino también por tener la osadía de, en palabras de Rahner, "saltarme" muchos siglos de especulación alrededor de esa cristología clásica ${ }^{\text {th }}$. Pero no le costará mucho al lector darse cuenta de que la posición de los teólogos liberales del siglo XIX, quienes eran el blanco de las críticas de Rahner, es totalmente diferente del doble Kraista Sutra que propongo en la tercera parte como fundamento de una cristología de alianza, donde también defiendo la lesis de Rahner de que la cristología clásica fracasó al no abordar adecuadamente el aspecio de la realidad de Jesús como el crucificado-resucilado, el mediador de la salvación ${ }^{17}$.

\section{Hacia una agenda leológica común}

La primera implicación del cambio de paradigma que propongo es aceptar la insistencia de los reformadores en que "la fe y la promesa se corresponden una a otra" (fides et promissio sunt correlativa) ${ }^{\mathrm{jk}}$. Lo que corresponde a la fe no es una revelación como lo ha estado enseñando (y lo continúa presuponiendo en su praxis curial) la Iglesia romana, sino la promesa divina, que respira esperanza. La fe no es primariamente una realidad que gira alrededor de verdades reveladas por Dios, formuladas con precisión por la Iglesia para satisfacer a la mente humana que cuestiona, sino que es fidelidad a un Dios fiel, quien ha hecho una promesa de salvación.

Por eso, no aceptamos que la leología - y a fortiori la crislología- sea definida unilateralmente como fides quaerens intellectum (fe que busca entender). Esta definición de teología está basada en el modelo del logos que llevó a los escolásticos a subordinar la facultad del amor a la facultad del entendimiento

16. Karl Rahner, Theological Investigations, Vol. XVII (Jesus, Man and the Church) (Crossroads New York, 1981), Pp. 24-28.

17. Ibid. pp. 28-30.

18. J. Moltmann, Theology of Hope (Londres, 1967), p. 44. 
(voluntas sequitur intellectum: "la voluntad sigue al intelecto"). En una teología del dabar, la intelección viene del amor y de la fidelidad, o, por ponerlo en lenguaje joanneo, quien no ama al prójimo no conoce a Dios (1Jn 4, 8.20). La praxis es la primera formulación de una teoría. Puesto que la fe (en las Escrituras judías) significa estor junto a la palabra que uno oye, la realidad en que uno es, determina lo que uno ve. La fidelidad a la alianza de amor es la fuente de conocimiento, de un conocimiento que es salvífico. Pues lo que genera intelección es el encuentro con quien es nuestro amor y nuestra salvación.

Moltmann sugiere la spes quarens intellectum (la esperanza que busca entender) como la altemativa apropiada a la fides quarens intellectum (la fe que busca entendimiento) ${ }^{14}$. Quisiera proponer una alternativa más bíblica y menos escolástica: fides sperans salutem (la fe que espera la liberación), sutra, por cierto, que se encuentra en la Constitución sobre la Iglesia del Vaticano II.

Ella [María] sobresale entre los humildes y pobres del Señor, que de él esperan (sperant) con confianza y reciben la salvación (salutem), (Lumen gentium, 55).

Así, María, el modelo de la Iglesia, "sobresale" (praecellit), es decir, "aparece llamativamente", entre los "humildes y pobres", que esperan y, por lo tanto, reciben la salvación. La Iglesia que está claramente presente entre "los pobres y los humildes" a la manera de María, sperans salutem (esperando la salvación) y recibiéndola, tiene una fe que se despliega a sí misma como una teología de liberación (o salvación) ${ }^{31}$. Y como Dios es salvación-liberación (eso es lo que significa literalmente el nombre "Jesús"), "esperar la salvación" es esperar el amor que Dios es en su misma realidad y que Dios pronuncia como su propia palabra, es decir, Jesús. Esta es la fons et culmen (la fuente y culmimación) de una auténtica crislología.

Los "pobres y humildes" son los sperantes (los que esperan) por excelencia. Esperar es aquello de lo que son más capaces. La liberación que anhelan es un mundo nuevo de amor, en el cual podrán disfrutar de felicidad total o "beatitud". Esta esperanza se expresa en sus cantos y oraciones, en sus ritos y fiestas, en sus mitos y parábolas, y en sus luchas del día a día, mezcladas con fracasos e incluso con pecados. Es una esperanza que está marcada por la tensión entre la resignación, casi desesperada, en su adversidad presente y la certeza implícita de que en el horizonte se avizora un futuro mejor. Lo que sueñan los pobres es lo que también su socio y compañero de alianza sueña por ellos. Estos anhelos secretos ("esperanza") emanan de una profunda e implícita convicción ("fe"), en

19. Ibid., p. 33.

20. La Jistinción entre "liberación" y "salvación" debe ser considerada como un construclo mental. Véasc, God's Reign for God's Poor (cfr. Nota 1). Capilulo 2. 
una posibilidad de salvación ("amor"), dada de antemano, la cual, en términos biblico cristianos, se conoce y se nombra mejor como una promesa de liberación hecha por alguien que es fiel.

Así, en los evangelios, los pobres, es decir, los excluidos socialmente (leprosos y deficientes mentales), los marginados religiosamente (prostitutas y publicanos), los oprimidos culturalmente (mujeres y niños), los dependientes socialmente (viudas y huérfanos), los minusválidos físicamente (sordos y mudos, lisiados y ciegos), los atormentados psicológicumente (posesos y epilépticos), los humildes espiritualmente (gente sencilla temerosa de Dios, pecadores arrepentidos), parecen tener un cierto conocimiento previo de la liberación como aquello de lo que carecen, a diferencia de los fariseos y poderosos, quienes no sentían necesidad de salvación y, por lo lanto, no la esperaban.

Cuando Jesús, lleno del Espíritu (creỉble, por lo tanto), anunciaba la cercanía del reino de Dios (Mc 1, 15), eso sonaba en sus oídos más o menos de la siguiente manera: "Lo que ustedes están esperando ya está a su disposición, aquí y ahora, en mí; por lo tanto, prepárense a cambiar". Era la buena noticia que tanto habían anhelado escuchar, la bienoventuranza (felicidad) de la que estaban a la espera, la salvación que habian esperado. Cuando escucharon esta palabra de ánimo, respondieron a ella juntándose alrededor de él para convertirse en el primer núcleo del reino de Dios, un acontecimiento que sólo llega ser un fenómeno visible después de la resurrección. La obediencia a la palabra es lo que les hizo bienaventurados (LC I1,28). María, quien recibió, concibió y alimenló la palabra en su cuerpo y en su corazón, fue fiel a ella hasta el momento cumbre revelador en la cruz. Los apóstoles dejaron su profesión y sus posesiones para seguir a la palabra, que los configuró como sus anunciadores. Ya en su nacimiento, los pastores que escucharon la buena noticia, actuaron de acuerdo a ella, yendo a encontrar la palabra de salvación, en condiciones sociales humildes. Simeón y Ana, que esperaban la salvación, la reconocieron y proclamaron. Los pobres y humildes tienen una inclinación connatural para oír, reconocer y responder a la palabra.

Detengámonos un momento para responder a una objeción. Los que abogamos por esta cristología de alianza no raras veces somos acusados de "idealizar" a los pobres. Esla queja contra la teologia de la liberación, simplista y prejuiciada, proviene al menos de tres grupos de cristianos: los liberales, los curialistas y parte de la élite intelectual en Asia. Pero antes de responder a sus crílicas, hay que explicitar algunos presupuestos cristológicos, que se esconden tras cada una de estas tres posturas anti-liberacionistas.

Los liberales, tanto en occidente como en el este, han optado por un Cristo $\sin$ la cruz, por un cristianismo confortable, que ha hecho desaparecer, precisamente, lo que define "lo cristiano" como singularidad irrepetible de Jesús (véase la tercera parte, 2). No pueden ver el papel salvífico de las mayorías de los 
pobres sufrientes en la liberación de los ricos, porque ven a los poderosos de este mundo como los liberadores de los pobres. No parecen entender que sólo una creencia secular en el Cristo colonial, que ha sido rechazado por las masas asiáticas, sirve de fundamento a una tal visión.

Los curialistas romanos, por su parte, están acostumbrados a hacer teología en el marco de la práclica del gobierno eclesiástico. Su eclesiología, al menos para quienes la vemos desde la distancia, corte el peligro de dejar que la Iglesia llegue a ser -exageradamente- un cuerpo euro-eclesial, que puede ocultar a Jesús, sú cabeza. Más aún, ven a los pobres como una cruz sin Cristo, de modo que hay que llevar a aquéllos a Cristo a través de una "evangelización directa" (eufemismo por "proselitismo"). Nuestra firme convicción es que donde está la cruz, allí está Cristo presente (ubi Crux, ibi Christus), porque Cristo es la alianza de Dios con los pobres, pero esto sonaria a los guardianes de la ortodoxia a infiltración de "la dictadura del proletariado" marxista en la teología. El servicio a los pobres es, entonces, relegado a un segundo nivel de lo que, en la teología curial, es conocido técnicamente como promotio humana (desarrollo humano). Al parecer, esto no dejaría de ser un mero instrumento para el proselitismo, mientras que el objeto de la le crisliana sería supuestamente otra cosa muy distinta: el "Cristo" que es encontrado en la devoción personal y en los sacramentos eclesiásticos. Esta postura es el resultado natural de una eclesiología que ha como engullido la cristología.

Por último, hay algunos intelectuales asiáticos cuyas teologías giran exclusivamente alrededor de las soleriologías metacósmicas de Asia, en diálogo sofisticado con sus defensores altamente escolásticos, no familiarizados con la religiosidad cósmica de los pobres - la gran mayoría de la población asiática- o que muestran desdén hacia ella. Desechan nuestro énfasis en los pobres como exageración romántica, porque la suya es una cristología sin eclesiología, exactamente lo opuesto a la teología curial (una eclesiología sin cristologia). Su Cristo gnóstico es una cabeza sin cuerpo. Les es difícil aceptar nuestra convicción de que los pobres de Asia, la mayoría de los cuales son no-cristianos, forman el verdadero cuerpo de Cristo que (lodavia) no ha reconocido y nombrado a su cabeza"1.

Dicho esto, podemos ahora responder brevemente a sus acusaciones. En primer lugar, nunca hemos dicho que las diversas calegorías de pobres que hemos mencionado estén exentas de pecado por el mero hecho de ser pobres. La palabra "pobre" es una especie de abreviación biblica para mencionar varios grupos de gente sin poder, incluyendo a los que son excluidos por pecadores, como queda claro en la enumeración que hernos hecho más arriba. Por lo tanto, no mantenemos

21. Véase A. Pieris, Fire and Water. Capítulo 7 (originalmente publicado en Concilium 1993/2, pp. 33-47). 
en modo alguno que los pobres son justificados o santificados por su miseria. Esto equivaldría a idealizar al pobre e iría contra los fundamentos de cualquier teología de la liberación. Sin embargo, sigue siendo verdad que Dios los elige como socios-compañeros de su alianza, no porque sean santos, sino porque son pobres. Ser pobres y sin-poder y ser rechazados por pecadores e indignos es el criterio de su elección. Este parece ser el esquema general de elección tal como aparece en la Biblia.

En segundo lugar una elección divina no es motivo de exclusivismo, porque la elección es para una misión, es decir, alguien es elegido no por encima de otros, sino para otros. Los sin-poder son elegidos para confundir a los poderosos, los pobres son convocados a ser mediadores de la salvación de los ricos y los débiles son llamados a liberar a los fuertes.

En tercer lugar, la salvación de los pobres depende de su fidelidad a la misión para la que han sido elegidos. Su salvación se constituirá en la aceptación y el cumplimiento de su obligación de acompañar a Dios, dando testimonio y proclamando la buena noticia. No es una tarea fácil para ellos. De ahí que quienes son pobres debido a las circunstancias tienen que ser "concientizados" en la misión que Dios les ha dado y tienen que ser despertados de su pasividad por el minislerio de aquellos que son pobres por elección. Moisés, por ejemplo, renunció a su posición privilegiada en la instilución opresora y se identificó voluntariamente con los oprimidos a los que consideró como el pueblo mesiánico y a quienes, por lo tanto, acompañó a salir de la casa de esclavitud a la tierra de la libertad (cfr. Hebr 11, 23-31).

Pero Israel luchó y con Irecuencia fracasó en la misión para que fueron elegidos, y así con frecuencia se separaron de Dios, tal como se lo recordaban los profetas; $y$, sin embargo, siempre hubo pobres entre ellos, el resto, que llevó a cabo la misión. También la Iglesia fue fundada como una comunidad de "los pequeños" (mikroi, una palabra clave en Mateo)"2. Pero en pocas décadas, también esta comunidad comenzó a adorar a la bestia de Roma de la que se habla en el Apocalipsis. Para los elegidos la elección es un desafío continuo a permanecer fieles a su misión a pesar de los fracasos. Esta es la razón por la cual, de vez en cuando, Dios hace surgir del resto comunidades proféticas.

El resto es una categoría que designa a quienes, por su pobreza (involuntaria o voluntaria), esperan incesantemente la liberación o la salvación (sperantes salutem), en lugar de buscar una apropiación conceptual de la verdad salvífica (quaerentes intellectum). A estos pequeños, la salvación les llega juntamente con la revelación, el amor les llega con el conocimiento y la comprensión de los

22. E. Schillebecckx, Ministry: Leadership in the Commnity of Jesus Christ (Nueva York, 1981), p. 21. 
secretos del reino de Dios (Mt 11, 25-30). Así, la verdad que salva les es revelada en el contexto de la esperanza generada por la palabra de la promesa, pronunciada por un Dios fiel, en una perspectiva escalológica. Dice Moltmann:

El lenguaje de la escalología cristiana no es el logos griego, sino la promesa que ha sellado el lenguaje, la esperanza y la experiencia de Israel. Israel encontró la verdad de Dios no en el logos de la epifanía del elemo presente. sino en la palabra de promesa que genera esperanza"

\section{Segunda parte}

\section{Un triple cambio en la metodología}

\section{Encarnación versus crucifixión}

Resumamos lo que hemos dicho hasta ahora: una comprensión intelectual de Cristo que precede al encuentro con la palabra de Dios (la cual es Jesús, expresándose a sí mismo como la doble palabra-mandamiento de amor a Dios y al prójimo) es gnosis, que no resplandece con el amor del ágape, una especulación que no evoca el amor, que es nuestra salvación. Es cristología sin soteriología, algo tan imposible y sin sentido como "sal que no sala". Tal sería el intento de comprender el misterio de Cristo meramente a través de conceptos tales como naturaleza, substancia, divinidad y humanidad, lenguaje que lleva a abstracciones acerca de Cristo más que a un compromiso con él.

Además, estas abstracciones no sólo provienen de recurrir a categorías filosóficas como instrumentos de una mera explicación (en la línea de la especulación), según el modelo de logos, sino también de orra fuente relacionada con la anterior: el método que hace girar el discurso cristológico alrededor del misterio de la "encarnación", interpretada como unión hipostática.

Parece que hemos olvidado que las primeras reflexiones sobre la encarnación fueron una idea tardia de quienes ya habían captado el significado de la cruz como el culmen del proceso redentor y el lugar privilegiado de exaltación. La encamación, por lo tanto, fue la conclusión de un proceso de retrospección, hecho a la luz de la exaltación en la cruz (muerte-resurrección). Convertir la conclusión en la premisa mayor de una "cristo-lógica" es un error metodológico, que ha dejado su huella en la teología oficial del patriarcado de occidente, y aún más profundamente en los patriarcados de oriente.

Hay que persuadir a los teólogos de esta tendencia dominante a que retornen al orden de la revelación del Nuevo Testamento, según el cual la exaltación en la cruz es lo que da sentido a la dimensión kenótica de la encarnación, y no a la inversa. Si en el intento de reformular la gran revelación del cuarto evangelio, es

23. J. Moltmann, op. cir., pp. 40-41. 
decir, que "la palabra (pre-existente) se hizo carne", tuviéramos que recurrir al instrumental conceptual de la filosofía griega $-y$ al lenguaje religioso grecoromano- para entender términos como "eternamente pre-existente", "palabra", "se hizo" y "carne" (véase la parte tercera, 3) entonces, en la cristología sería imposible captar el espectáculo escandaloso del cuerpo de Jesús destrozado en el calvario. La "carne" que se hizo la palabra no fue sólo humanidad o naturaleza humana en lo abstracto, sino la concreta "persona humana", en situación de destrozo. Jesús, desde el momento de su concepción, emergió de un pueblo destrozado, como una persona destrozada ella misma. A esto es a lo que apunta Filipenses 2, 5-11.

Muchas de las sospechas que hoy se ciemen sobre los teólogos asiáticos y su comprensión de Cristo como uno en medio de muchos "portadores de un mensaje de liberación" (fundadores de religiones) provienen de una noción de encarnación que reduce la "came" de las Escrituras a la humanidad de la que hablan los filósofos. La unión hipostática de divinidad y humanidad en una persiona divina es aducida como la base de la singularidad irrepetible de Cristo como salvador universal, lo cual cuestionaré más adelante. Pero digamos desde ahora que es mejor poner la singularidad irrepelible de Jesús en el hecho de que él se convierte continuamente en la persona corporativa llamada el Cristo (aunque bien se pudiera encontrar otra palabra para decir "salvador"), en el cual lodos los compañeros-de-alianza o co-redenlores o co-agentes (synergoi) de liberación (es decir, las dos categorías de pobre) están en proceso de quedar unidos, junto con la totalidad del cosmos al cual ayudarían a co-redimir.

Hay que cuestionar, por lo tanto, una clara distinción entre soteriología $y$ cristología y el modo como cada una de ellas es definida. Algunos cristólogos (más en la línea protestante) reclaman que el enfoque de Jesús en el cristianismo más primitivo era más "soteriológico", es decir, que miraba hacia adelante, hacia la parusía o a la participación final de toda la creación en su resurrección, desde el acontecimiento cumbre de su muerte y su resurrección, mientras que en un período neotestamentario posterior, habría surgido un enfoque más "cristológico", que consistió en mirar hacia atrás (también a la luz de la resurrección, hacia su ministerio, su vida, su nacimiento, su pre-existencia en Dios y su subsecuente encarnación $)^{24}$.

Mucho mejor es evitar tales dicolomías que parecen ser el resultado de una doble visión, generada por la óptica analítica de la teología del lipo logos. Mejor es usar el término cristologia en el único sentido en el que debiera ser comprendido: una soteriologia que recibe su significado necesariamente del decisivo

24. Véase James D. J. Dunn, Unitiy and Diversity in the New Testament. An Inquiry into the Earliest Character of Christianity, Westminster Press (Philadelphia. 1977), Pp. 203ss. 
"momento escatológico" de Cristo en la cruz. Dios es siempre un Dios para nosotros, pues Dios revela su ser Dios en lo que Dios hace para nosotros. Dios es, por lo tanto, el salvador-creador, está, por ello, automálicamente implicado en lo creado y lo redimido. La cruz da fe de este dinamismo visible para todo el mundo de todos los tiempos. Lo que (Dios en) Cristo hizo en la cruz por nosotros, define, por así decirlo, quien es (Dios en) Crisio.

Ahora bien, la cruz es un lugar social, en el que acaece de una vez para siempre un conflicto social entre la soberanía (reinado) del Abba-Amma de Jesús, que confiere libertad, y el sistema esclavizinnte de dominación, inventado por los adoradores de Mammon (el dios dinero. el capital absolutizado). En la realidad de este conflicto, el "Jesús de ayer" (el Jesús pobre, a quien seguimos como sitss discipulos) muestra su prelensión de ser "el Cristo de hoy" (el Cristo víctima, a quien servimos como apóstoles). Esta "vocación" al discipulado y esa "misión" al apostolado constituyen, a la vez, el testimonio profético y el culto sacerdotal, a través de los cuales el reino de Dios, presente en Jesús el Cristo (autohasileia). es proclamado proféticamente, celebrado litúrgicamente y compartido universalmente. Esla cristología es, por lo tanto, un programa de liberación, que, simultáneamente, genera una teología, y no una especulación de la cual se debe sacar forzadamente una praxis, o una explicación filosófica, en la que hay que introducir artificialmente una soteriología con ulteriores especulaciones, o una doctrina declaratoria que, por ello, tiene que ser exigida por la autoridad.

Más aún, hay que prestar la debida atención a la fórmula de la Escritura "en los días morrales" y "como lo conocemos ahora" (2Cor 5, 16). Con esto no se hace referencia, ciertamente, a la humanidad y divinidad de Jesús respectivamente, como si ambas pudieran ser separadas, sino que se quiere indicar su participación en nuestra condición humana, por una parte, y su victoria sobre ella, por otra. Expresan dos momentos de la actividad redentora de Jesús que coinciden en la cruz. No son separables, como no lo son su existencia carnal, según la cual proviene de la tribu de David, y su ser constituido Hijo de Dios por la resurrección (cfr. Rom 1, 3-4). Pero la especulación cristológica, que se concentró puramente en la unión — sin mezcla — de la humanidad y de la divinidad en Cristo, llevó gradualmente a las definiciones de Calcedonia, en las cuales el nexo entre los "días mortales" y "como ahora lo conocemos" fue desvaneciéndose, al parecer, tras el pseudoproblema de armonizar la humanidad y la divinidad de Jesús en el logos divino. Y peor aún, este "problema" fue "resuelto" a expensas de su humanidad"s.

Este énfasis equivocado, que aparece en la crislología, puede ilustrarse, comparando dos momentos en que la lectio divina sobre "los días mortales" ha sido llevada a cabo por dos diferentes calegorías de pobres a lo largo de la historia de

25. Cfr. el comentario de Rahner, arl. cil., p. 28. 
la Iglesia. Han generado dos formas complementarias de "humanismo cristiano", no a causa de, sino a pesar de la cristología de Calcedonia. En ambos casos (uno del tiempo medieval y otro de la historia reciente, como veremos más adelante), una parte de los fieles parece haber enmendado la cristología del concilio por el modo en que la recibieron.

Como dice un historiador, la identificación de Crislo como el logos divino, de tal manera dominó el pensamiento de los padres griegos, así como el de influyentes padres latinos, lales como Agustín, que la así llamada devoción a la humanidad de Cristo surgió por primera vez sólo en asentamientos monásticos medievales de occidente (benedictinos y cistercienses), gracias a la costumbre de meditor la vida de Jesús, en las Escrituras (lectio divina) como motivación para imitarlo en sus virludes ${ }^{2 h}$. La influencia de "la literatura pagana de amor" en la recuperación de un humanismo cristiano, enraizado en el hombre Jesús ${ }^{27}$, parece que sirvió de acompañanle y precursora de muchas olras devociones que se han centrado en la humanidad de Cristo, como la devoción a sus heridas, su corazón, su pasión, su rostro, su cuna y su cruz. Este fenómeno atestigua "los días morlales" de Jesús, a través de una lectura de fe de las Escrituras, en el contexto del influjo de un humanismo que tenía su fuente fuera del cristianismo. El hecho de que, muchos siglos después, la versión jesuita de esta devoción a la humanidad de Jesús (el culto al Sagrado Corazón) luese condenado por los jansenistas como concesión al nestorianismo, muestra lo enraizada que estaba la teologia en el molde calcedoniano" ${ }^{24}$.

Comparemos ahora la génesis de esta espiritualidad humanista de la edad media con el surgimiento del humanismo liberacionista (no liberal), que ha caracterizado a la teología de la liberación, en la segunda mitad del siglo XX. También aquí el fenómeno masivo conocido como "la irrupción de los pobres", que claman por una nueva humanidad y un nuevo humanismo, fue abonado por una nueva forma de leer las Escrituras, no sólo por aquellos que han opıado por ser pobres (monjes y religiosos) como en la edad media, sino especialmente por aquellos que han sido forzados a ser pobres bajo el impacto de la codicia organizada. Este fue el origen de la reologia de la liberación, que es el marco de la cristología, que ahora propongo.

26. Ewert Cousins, "The Humanity and the Passion of Chrisl", en Jill Rail et al. (cds.). Christian Spirituality, Vol. II: High Middle Age's and Reformation (World Spirituality Serics) SCM (Londres, 1989). pp. 37\$ss.

27. Jcan Leclerq, Monks and Love in the Twelfth Century France (Oxford, 1979), passim.

28. En God's Reign for God's Poor. Capílulo 5, lambićn he Jcmostrudo como cl modclo calccdoniano de la persona divina que asumc la naturalcza humana ha dejado su huella indeleble en el paradigma contemporáneo de espirilualidad, que se expresa en ıćrminos de modelos dualísticos, lales como contcmplación-acción, fc-justicia, salvación-libcración. 
Ahora, "el seguimiento de Jesús (tal como él fue) en su vida mortal", propio del monje medieval, que desencadena una devoción personal a Jesús, queda complementado por los mismos pobres, que reconocen a "Cristo como ahora lo conocemos", como a su propio acontecimiento pascual, e invitan a los no-pobres a buscar su salvación, participando de ese mismo acontecimiento. Ambos fenómenos surgen de una lectio divina. La cristología implícita en este doble movimiento parece respaldar la insistencia del cardenal Martini en que la espiritualidad abarca tanto lo personal, el servicio al rey (una devoción apasionada a Jesús, el Cristo), como el servicio al reino ( $i$ se tratará, presumiblemente, de un servicio profético a los pobres como representantes de Cristo? $)^{24}$.

Con estas observaciones ya hemos comenzado la discusión sobre el segundo cambio en metodología, que vamos a desarrollar en mayor detalle, es decir, el modo correclo de leer las Escrituras, el lipo de lectio divina que nos asegura un compromiso con Cristo como la doble palabra eficaz de Dios, que desarrolla un programa de liberación.

\section{Hermenéutica como lectio divina}

Las Escrituras son documentos de fe recopilados y editados con la finalidad de suscitar nuestra fe y la fe de nuestra posteridad, comunicando lo que "Ios pobres y humildes que esperaron y recibieron la salvación" ( $L G 55)$ tenian que decir sobre lo que vieron y oyeron. De aqui que el medio de la comunicación es narrativa y drama, parábola y alegoría. metáfora y similes, himnos o poesía, paraleipsis e hipérbole. Estos son, en efecto, instrumentos capaces de evocar en los oyentes la experiencia de aquellos que han sido testigos de la palabra como acontecimiento.

Creo, por lo tanto, que cualquier intento por exprimir la "verdad real" de la palabra de la Escrilura, prescindiendo de los medios evocadores de los escritores biblicos en la comunicación de la le, tal como lo acabamos de decir, por ser aditamentos mílicos o desechables, es un csfuerzo tan inútil como el de producir música prescindiendo de los sonidos y su composición, o ciptar la belleza de una escultura desechando el material del cual está hecha. El uso del método de "desmitologización" se debe restringir a visiones culturalmente obsoletas (ver la sección 3 más abajo) y no debicra ser aplicado a estos medios evocadores. Asi como el enfoque más críico a una obra de arle (lo cual es verdaderamente necesario) está basado en una experiencia estética, así también. inclusoso el estudio más crílico de las Escrituras se fundamenta en nuestro encuentro con la palabra, en el Espíritu.

29. Carlo Maria Martini. The Woman Among Hor People: A Spirinal Journey into the "Planet Woman". St. Paul Publication (Slough. IOR9: Indian edilion. Bombay, 1900). p. 86. 
También hay que valorar el hecho de que, dentro de las mismas Escrituras, se nota una revisión y una re-edición periódica de varias formas de comunicar la fe, de acuerdo a las necesidades de la fe de cada una de las nuevas comunidades. Hay que agradecer realmente este modo de proceder del mismo texto sagrado, que consideramos normativo para nosotros. Nos invita a no fosilizar el mensaje, convirtiéndolo en fórmulas doctrinales "irreformables" o "definitivas", sino que nos invita a recrear constantemente el kerigma, en el contexto de la situación histórica de nuestros pueblos, especialmente de los pobres. Esta es, en verdad, la forma en que el Espíritu de Cristo nos "trae a la mente" lo que Cristo (la clave hermenéulica de las Escrituras) nos ha enseñado (Jn 14, 26), ciertamente, no fijando ni enmarcando las fórmulas de fe de una vez para siempre. El Espíritu, la energía siempre creadora que expira la palabra, constituye el principio eterno, que nunca muere, de la tradición sagrada, la que guía la continua re-lectura de las Escriluras, en cada generación.

Eslo significa también que la especulación sobre "el Jesús histórico", que se esconde tras el Cristo de la fe y que acaba ofreciendo lo que Ray Brown llama una "figura bidimensional de Jesús", puede conducir a un callejón sin salida. Aun aceptando la posibilidad de tal investigación, Brown expresa también la siguiente reserva:

Puesto que la investigación deja de lado la percepción cristológica de Jesús por parse de sus seguidores, la figura bidimensional que emerge carecerá muy especialmente de profundidad teológica y espiritual, porque reflejará lo que los investigadores quieren resaltar. La idea de que la fe cristiana deberia depender de la reconstrucción del Jesús histórico es un peligroso error ${ }^{u 1}$.

Nuestro discurso, por lo tanto, no es una discusión especulativa sobre la posible dialéctica entre el Jesús histórico y el Cristo del kerigma, entre el Jesús en sus días mortales y el Cristo como ahora lo conocemos. Nuestro discurso es más bien proclamación martyrial (apoyada por testigos) de que el JESÚS a quien nosotros seguimos, siendo pobres como él lo fue "en sus días morlales", ES EL CRISTO de hoy, "lal como ahora lo conocemos" (como el juez escalológico, en su gloria del fin de los tiempos), a quien nosolros servimos en sus representantes, las víctimas de las naciones.

En este esquema la distinción tradicional entre nuestro servicio a Cristo en los pobres (lo que antes se llamaba "obras corporales de misericordia", consideradas como una forma inferior de servicio) y el servicio de Crisio a nosotros, a Iravés del ministerio de los sacramentos y la predicación ("obras espirituales de misericordia", supuestamente más valiosas que las anteriores), configuran una cristología, en la que el pan y los pobres son ambos sacramentos de salvación, el

30. Raymond Brown, An Introduccion to the New Testament, Douhleday (New York. 1997), p. 106, énfasis uñadido. 
pan que apunta a los pobres". El Cristo que nos sirve con la palabra y el sacramento, y nosotros sirviendo a Cristo en los pobres, implican un alimentarse, inseparablemente recíproco, del único cuerpo de Cristo, en el cual Jesús llega a ser juntamente con nosotros, por medio de este servicio mutuo. Estos dos ministerios no pueden separarse. "La solidaridad sufriente con los pobres e insignificantes es una nota esencial de la apostolicidad del ministerio, pues es una nota apostólica de toda la comunidad de Jesús":32. De hecho, esta diakonia recíproca es una constante clave hermenéutica en las Escrituras para entender lo que significa entender a Cristo (Verbum Dei 25). Si se me permite especificarlo todavia más, entender las Escrituras es entender a Cristo como el pacto de Dios con los pobres.

De este modo llegamos a nuestra observación final sobre la segunda dimensión del cambio en metodología: toda hermenéutica recibe su autenticidad del modo como las Escrituras son leidas por los pobres a quienes el reino de Dios es ofrecido primariamente como buena noticia. Las dos categorias de "pobres" arriba mencionadas (es decir, "los pobres por las circunstancias", quienes son los vicarios de Cristo, y "los pobres por elección", es decir, los seguidores de Jesús) son elegidos, a la vez, como los herederos y los porradores del reino de Dios, asi como son también los destinatarios primarios y los anunciadores cualificados de Ja buena noticia"3.

La mayoría de los pobres llamados por Dios para ser los socios de la alianza de Dios en el proyecto de liberación no son cristianos. La primera categoría (victimas de Mammon, que representan al "Cristo" como lo conocemos) constituye la mayor parte de la población del mundo, que se concentra en el Asia no cristiana. La segunda categoría (los que renuncian a Mammon y siguen a Jesús "como él fue en sus días mortales") incluye a tantos co-agentes de liberación, guías en el camino de la justicia, descubridores y anunciadores de la verdad salvífica, fundadores y defensores de otras religiones. Estos no son rivales en una campaña proselitista para conscguir conversiones, sino socios en una misión común. Jesús, en quien Dios se convicrte en alianza con los pobres, necesita su colaboración para Ilegar, junto con ellos, a la plenitud de su ser Cristo. Jesús no puede ser Cristo sin ellos.

Pues aunque Jesús es tolalmente Cristo (tolus lesus esł Christus), no es la totalidad de Cristo (non est totum Christi). pues la totalidad de Cristo no es Jesús (folus Christus non esf lesus). En otras palabras, Jesús está indavía en proceso de alcanzar el ser-Cristo tolal, y no llegará a serlo sin reunir a sus compañeros de alianza. De aquí que Cristo no debe ser concebido meramente como una "persona", en el sentido de una "sustancia individual de naturaleza racional", sino que

31. Véase God's Reign for God's Poor, Capilulo 3.

32. E. Schillebeeckx, Ministry, p. 37.

33. Véasc God's Reign for (jod's Poor. Capítulo 5. 
tiene que ser encontrado como una "persona corporativa", que es una carne y una sangre con todos los pequeños, aquel que está siempre comprometido con el proceso de salvar, reunir, integrar a todos y a todo en lo que, en lenguaje cristiano, es confesado como la plenitud de Cristo.

De aquí que en el proceso de crislogénesis, el magisterio de los pobres debe gujar los dos minislcrios llamados a ser "servidores de la palabra" (cfr. Verbum Dei, 10), a saber, el asi llamado ministerio académico de los teólogos y el ministerio pastoral de los obisposs. Cuando los primeros teólogos (evangelizadores, profelas y maestros) y los líderes de la comunidad (obispos y ancianos) formaban parte del magisterio de los pobres (como lo fueron los doce, cuya misión continuaron aquéllos), el problema pudo no haber sido muy agudo. Pero en la aclualidad, estos dos ministerios no pueden ser tratados como magisterios hasta que no recuperen su auloridad y vuelvan a ganar su credibilidad, a través de su solidaridad con esas dos calegoríss de pobres, a quienes Dios ha escogido como compañeros en la praxis de su liberación y como maestros de las naciones en los caminos de Yahweh. De esta manera, lo que se ha dado en llamar "teología de la liberación" no se basa necesariamente en la superioridad de "la praxis sobre el conocimienı", principio que habría sido heredado del marxismo, como Ratzinger parece insinuar", sino en comprender y partir de la palabra de Dios como dabar (un deseo práxico que desencadena una prexis portadora de conocimiento), que es obedecida por ambas categorias de pobres, en las comunidades crislianas de base o (como en Asia) en comunidades humanas de base.

Paulo D. Siepiersky ha documentado el patético estado de pobreza en que vivia la gran parte de creyentes, mientras se debatían los dogmas cristológicos, en el concilio de Nicea, sin que se hiciese presente, ni siquiera en un comentario de pasada, su difícil situación, porque la finalidad del concilio era conseguir la unidad imperial, aun cuando asegurase que su finalidad era la de la unidad cristia$n^{\text {nh }}$. Un juicio semejante pudiera hacerse sobre otros concilios cristológicos que nos entregaron abstracciones sobre un Dios que se hacía humano en Cristo, pero que no supusieron ningún acicate para escuchar al Espíritu de Dios gimiendo y clamando con la voz de los oprimidos.

34. Para una discusión más decallada de csta tcsis, vćasc mi "Prajna Pitha: Seat of Wisdom: Toward a Marian Formation of the Ministers of the Word", Vidyajyoti Journal of Reflection, Vol. 63, N. 1, cnero de 1999, pp. 7-20, y N. 2, febrero, pp. 103-118.

35. Josef Ratzinger, "Current Situation o Faith and Theology", Boletin Ecleisiástico de Filipinas, 73, N. 799 (1997). pp. 132. Esta sospecha implica un en[oque negativo de] marxismo por parte de quiencs quizás no ven la incompatibilidad del capitalismo con cl cristianismo bíblico. Por lo que loca a la necesidad de una "reccpción crílica" del maxismo, especialmente en el área de la economía y la ética social, véase Ignacio Ellacuria, "Tcologic der Bcfrciung und Marxismus", Orientierung, 50/11, 15 de junio (1986), pp. 127-131.

36. Paulo D. Siepierssky. "Nicea and the Marginalized", Theology Digest, $38 / 1$ (1991), pp. 23-29. 
Es tiempo de reconocer como dalo de la revelación que no hay ningún problema (ni filosófico, ni de otro lipo) en el hacerse hombre de Dios, porque la humanidad es la propia creación amorosa de Dios, algo bueno y noble; Dios pudiera haber devenido flor sin ningún sonrojo. De hecho, Dios está en toda la creación. Lo que fue escándalo para los creyentes tradicionales y locura para los pensadores gentiles (por repetir el veredicto paulino) es que Dios, al hacerse una persona humana, escogió el nacimiento, la vida y la muerte de los deshumanizados (los humiliores de un imperio, basado en una economia de esclavos), y que Dios en Cristo etapeinosen, es decir, se abajó a sí mismo a la condición social de esclavo, en la manera de vivir y especialmente en la manera de morir en cruz. (Fil 2, 5-11), pues tal condición social no era una creación producto del amor de Dios, sino el fruto pecaminoso de la codicia humana. Dios, por amor, cayó en el abismo del pecado. "Siendo (uparchon) de condición divina" significa "precisamente porque era divino", no "aunque fuese...", como traducen muchos. Gracias a su naturaleza divina pudo humillarse a sí mismo hasta asumir una forma de muerte reservada a los estratos más bajos de los humanos. Esta es literalmente la crux de cualquier cristología válida. Sólo esto define lo cristiano como aquello que hace de Jesucristo una realidad única (ver la tercera parle).

De esto Irala la cristología: del escándalo y de la locura que asumió la palabra de Dios en sus días morlales. Cualquier intento de reducir el impaclo de este escándalo o la magnitud de esla locura para hacerla "aceptable" a los piadosos y "razonable" a los sabios sería repetir el error de los "locos" gálatas (Gal 3, 1-5), error que hizo suyo después, en gran manera, la cristiandad romanizada, a pesar de las fuertes advertencias del Apocalipsis a las iglesias de no correr tras la "bestia atractiva" de la pompa imperial y del poder, y de la llamada — por el contrario-a identilicarse con "el cordero degollado" como la fuente de la salvación. De ahí que el punto luminoso del Concilio Vaticano II fuese la llamada de Juan XXIII a convertimos en Iglesia de los pobres. Eslo fue, al menos, una dimensión del pentecostés que deseaba que se hiciese realidad en la Iglesia. Una cristología del postconcilio liene que responder a esa llamada de la cruz, que nos dejó el papa carismálico.

Volvamos a la convicción cristiana de los inicios (no tenida en cuenta por los concilios cristológicos) de que lo que priva de la comunión no es la negación de un dogma que nosotros, humanos, hemos formulado, sino (para usar otra expresión bien conocida teológicamente) nuestra "opción fundamental", es decir, la orientación radical e irreversible de nuesıro ser por la cual nosotros, farisaicamente, excluimos a Dios y al prójimo de nuestra vida. Eso es pecado, tal como lo entendió Jesús ${ }^{17}$. Obviamente, el objeto de tal exclusión no es necesariamente un tipo de Dios, definido filosóficamente como el ser existente por sí

37. Véase Jürgen Moltmann, Jesus C'hrist for Today's World. SCM Press (Londres, 1995), pp. 15-16. 
mismo, el Absoluto inmutable, el Poder impasible, el Motor inmóvil, de quien los ateos se ríen y expulsan de sus vidas, sino el Dios uno y verdadero, que se ha atado a sí mismo a ser el pacto de defensa con los pobres contra los principados y poderes de Mammion. Nuestra fe, como lo implica la raíz hebrea amn, es nuestro "mantenernos firmes" ante ese pacto o palabra de promesa, en cuanto se ha encamado por nuestra causa y ha morado en medio de nosotros como Cristo Jesús. Para estar en comunión con este Dios de Jesús, tenemos que estar en comunión (o solidaridad) con los pobres que forman su cuerpo visible en la tierra. Pues el juicio final de excomunión no está basado en nuestros dogmas, sino que es pronunciado sobre nosotros, ya ahora, por el juez escatológico, en y a través de los pobres de hoy, quienes actúan como los verdaderos vicarios de Cristo en la tierra (Mt 25, 31-47), y por nuestro prójimo, a quien el mismo Jesús ha definido como víctima de la explotación, que irrumpe en el camino de nuestra vida y nos otorga, a cambio, vida eterna por nuestro servicio del amor (Lc 10, 30-35). La excomunión del final de los tiempos acaece ya ahora.

Tal acto de fe en la alianza nos espolea para crecer en el verdadero cuerpo de Cristo, es decir, una Iglesia que lleva las cicatrices de los pobres. En otras palabras, este tipo de fe no es un "asentir intelectual a una doctrina" mediada por dogmas, sino una adhesión personal y comunitaria a Cristo, la Persona Corporativa, en la cual el Dios trino configura una continuidad-de-cuerpo (bodycontinuum) con los pequeños de la tierra, convocando a la Iglesia a ser el sacramento de ese mismo cuerpo. Por esáa razón, la pretensión de la Iglesia de ser el cuerpo de Cristo debe ser verificada según la confesión de Cristo de que las víctimas de las naciones son su "yo", su persona, su cuerpo (MI 25, 31ss). Si la Iglesia no es coextensiva con ese cuerpo, ¿hasta qué punto es la lglesia de Cristo? De nuevo, la pretensión de la Iglesia de hablar en nombre de Cristo se tiene que dejar verificar en sí su voz es sincrónica con el grito del Espíritu en los gemidos de los pobres. Esta es la eclesiología que está implicada en la nueva alianza de su cuerpo y sangre, que celebramos al partir el pan y compartir el cáliz ${ }^{\text {.3. }}$.

\section{El lenguaje de arriba-abajo y las cristologíus ascendentes-descendentes}

La mayor anomalía en la teología actual es que, a pesar de un celo excesivo por desmilologizar y a pesar de que han Iranscurrido tantos siglos desde la adopción del modelo heliocéntrico del universo de Galileo, la teología permanece inmersa en el lenguaje arriba-abajo, que los escritores biblicos adoptaron de la visión babilónico-canaanita de hace más de dos milenios y medio. Y el Nuevo Testamento lo acepta tanto como lo acepla el Antiguo. El binomio descensoascenso es parte del lenguaje cultural de la Biblia, aunque no sea el núcleo de su contenido revelador.

38. Para un ulterior desarrollo de esta idea, véase God's Reign for God's Poor, Capítulo IIl. 
Durante su exilio en Babilonia, los judios, que mantenian una memoria vivida del Yahweh del éxodo, tenian que presentar a la nueva generación, así como a las naciones que los sometían, una visión de Yahweh como ser transcendente, y para cllo tenían que hacer uso de los mitos de la creación de aquellos pueblos. Para ofrecer una visión alternativa de la creación, una visión que no comprometiera la soberanía de Yahweh, cl pueblo judío tuvo que usar la visión estática del mundo de sus vecinos no judios ( $c f r$. Gen 1 y 2 ). En esa visión del mundo, Yahweh residía en lo más alto de los cielos, mucho más allá de los cuerpos celestes, que no eran sino crealuras de Yahweh, y no divinidades, como, erróneamente, pensaban sus vecinos paganos. Los humanos, hechos a la imagen real de Yahweh, regían sobre la creaturas celestes y terrestres, pero permanecían sobre la tierra -muy lejos de las alturas-, con el sheol subierráneo esperándolos tras la muerte. Dios está arriba y los humanos abajo, con los muertos - silenciosos- en lo más abajo.

A esto hay que añadir que, mientras no hubo templo de Jerusalén, para acceder a Dios habia que llegar al sancta sanctorum en los cielos. La totalidad de obras de la apocalíptica judía (anteriores a Daniel) ha mostrado una teología de ascenso y descenso, asi como visiones simbólicas de las moradas superiores, lo que apoyaba la creencia en la ascensión de cierlos profetas"." Para alcanzar la morada de Dios había que ascender a los espacios celestes (Is 14, 13-14).

Este lenguaje se da por supuesto en el Nuevo Testamento. El "Espíritu" descendió sobre Jesús (Mt 3, 16; Mc I, 10) y "vino del cielo un ruido como el de una ráfaga de viento impetuoso" anles de llenar el cuarto en que se encontraba la comunidad primitiva (Hech 2,2). Sólo Jesús "ha subido (anabebeken) al cielo" porque sólo él es "el que ha bajado (katabas) del cielo" (Jn 3, 13). De esta forma, la aparición de Jesús, descrita como descenso desde arriba y su vuelıa al Padre como ascenso $(\mathrm{Ef} 4,8)$, se convirtió en parte del lenguaje del kerygma y se introdujo en la más temprana confesión de fe: que Jesús "descendió" (karelthonta) para hacerse carne y "ascendió" (anclthonta) después de la resurtección, como lo dijo el primer concilio de Nicca". Jesús "descendió" al sheol después de su muerte (Ef 4, 9; Heb 7, 14). Ascenso y descenso llegaron a configurar, pues, un lenguaje tan natural para el creyente de entonces que Lucas no pudo representar la reunión final del Jesús resucitado con el Padre sino con la imagen gráfica de Cristo traspasando las nubes y desapareciendo en el cielo, todo ello seguido del anuncio de que volvería (es decir, hajaria) de la misma manera (Hech 1, 9-10).

39. Véasc Marıha Himmmellarb, "From Prophccy to Apokalypsc: The Book of the Walchers and the Tours of Heaven", en Arthur Green (ed.). Jewish Spirituality: From Bible Through the Middle Ages (World Spirituality Serics, cditado por Ewert Cousins, Jewish Spirituality, Vol. I) SCM Press (Londrcs, 1985), pp. 145-165.

40. Norman Tanner, (ed.), Decrees of the Ecumenical Councils, Sheed and Ward (Londres, 1990), Vol. I, p. 5. 
El debate sobre cristologia ascendente y cristología descendente está basado en un literalismo o en un fundamentalismo literario, pero no en una lectura adecuada de la mente de los autores humanos, que escribieron las Escrituras cristianas. Hemos adoptado un modelo obsoleto del universo -que no es un dato de la revelación- como escenario de la encamación y resurrección, y, consecuentemente, como escenario, quizás, de todos los otros dones y ministerios de la Iglesia. Como nos advierte Schillebeeckx, todo lo que venía "de abajo", en la comunidad en la cual moraba el Espirilu de Dios, fue considerado como "un don del Señor", porque

el Nuevo Testamento rebosante de alabanzas hacia los "dones de arriba", no conoce el contraste posterior entre lo que viene "de abajo" y lo que viene "de arriba" 4 .

Esta observación debe guiarnos también en la cristología. Rahner se refiere a la cristología clásica, tanto de las iglesias orientales como occidentales, como "cristologia vertical, encarnatoria y descendente". Ambas terminan en un callejón sin salida, pues la primera lleva a una teoría platónica y especulativa de la divinidad y de la humanidad, unidas en una y la misma naluraleza, y la segunda cae en la teoría feudal germana de la satisfacción. Ambas están en contraste con lo que él llama la "crisıología horizontal de la historia de salvación"4-. Esto es lo que en el lenguaje teológico convencional se denomina "cristología desde abajo". Este lenguaje de arriba-abajo, que proviene de nuestra percepción humana de un espacio estático tridimensional, no se puede evitar del todo al hablar de Dios y la salvación. Por ello, al emplear la metáfora, debiéramos tener cuidado de no expulsar a la cristología de la perspectiva promesa-cumplimiento de la historia de salvación, una perspectiva lineal que se mantiene coherentemente en las Escriluras".

Por la misma razón, hay que ser igualmente precavidos al aplicar la creencia índica en el avatara (descenso de seres divinos) para formular una cristología asiática. Más allá de la discrepancia bien conocida entre los presupuestos filosóficos y antropológicos de la doctrina de Calcedonia, por una parte, y la doctrina avarara de la religiosidad índica, por olra, el asunto se complica al usar el lenguaje de ascenso y descenso, como claramente lo ha demostrado Neuner ${ }^{\text {t4 }}$.

De aqui que la aparición de Jesús tiene que ser vista primariamente como un acontecimiento cósmico, que estalla desde dentro de la creación, como acontecimiento que ha sido esperado desde todos los tiempos: aperiatur terra et

41. E. Schillebecckx, Ministry, p. 5.

42. Rahner, op. cit., pp. 29-30.

43. Sobre esto hablaré en delialle más adelantc.

44. J. Neuner, S. J., "Das Christus-Mystcrium und dic indische Lehre von den Avataras", en A. Grillmeier and H. Bacht, (eds.), Das Konzil von Chalcedon, Geschichte und Gegenwart, Echter Verlag (Würzburg, 1979, Sa. cd.), |pp. 786-824), pp. 815 ss. 
germinet salvatorem! Nubes pluant jus/um! ("jaábrase la tierra y haga surgir al salvador! ¡Que las nubes hagan Ilover al justo!"), como cantamos en advienlo. Por ello, en Asia, recurrir al lenguaje de "descenso" (avatara) tiene que ser balanceado y corregido por el lenguaje de "emerger" (unmajjana en sanskrito, ummujjana en pali), lo cual, a su vez, siempre tiene que ser complementado con "convergencia".

También es interesante recordar que "cmerger-convergir" eran imágenes que fascinaban a Teilhard de Chardin, quien optó por una teologia del "Dios-adelante". modificando la teologia tradicional del "Dios-arriba". El hecho de que, más o menos simultáneamente y en total independencia, el filósofo hindú Sri Aurobindo pensaba de alguna manera en la misma línea, desde su propia iradición religiosa. sumergiendo el concepto avatara en la corriente emanacionista del pensamiento hindú, tendria que ser tomado en cuenta al desamollar una cristología indica.

De acuerdo a la cristología de alianza que estoy proponiendo, la palabra de promesa, que está ya actuando en la creación y en la historia humana desde el comienzo, emerge en "came y sangre", en la plenitud de los tiempos como Jesús de Nazaret, el cual crece hacia el ser-Cristo omniabarcador, hacia el que converge toda la creación y toda la historia como hacia su futuro último. Aquí, la cristologia, que es soleriologia, conslituye el movimiento hacia el futuro, que imumpe en el presente.

Esto nos lleva a la tensión entre el Dios-arriba y cl Dios-adelante, es decir, entre el logos, que entra en la historia desde la esfera divina arriba, y el dabar, la palabra de promesa, que crea historia en el proceso de su plenificación. La cultura greco-romana no es la que realmente originó esta tensión, pero sí la acentuó. En el mundo hebreo, la tensión comenzó, quizás, de otra forma, como tensión entre el templo y la tienda; entre el templo de Cedar, donde Dios es invitado por los seres humanos a morar (yasab) para poder ser alcanzado, a través del culto, y la tienda, en la cual Dios siempre se movía (halak) con su pueblo, en busca de una tierra (cfr. 2 Sam 7, $1 \mathrm{ss}$ ).

Ya en el pentateuco, o en el hexateuco (Génesis-Josué), nolamos la tensión en otra forma: la "tradición de asentamiento", que ve el cumplimiento de la promesa en la concesión de la tierra a las tribus (Jos 21, 41-43), y la "iradición del Sinaî", donde la tienda se convierte ella misma en el lugar de la plenificación final, la experiencia de la presencia y de la gloria (kavod) de Yahweh (Lev 9, 23. 24). ¿Se trataba de "la tienda de la reunión", que anticipaba el culto del templo? De acuerdo a ciertas hipótesis controvertidas, esta tensión surgió cuando los redactores posteriores pusieron juntas dos diferentes tradiciones de un periodo anterior. Pero aunque esta hipótesis no fuese aceptada, permanece el hecho de que la tensión ha cristalizado para siempre en las Escrituras hebreas.".

45. Jon D. Levenson, "The Jerusalem Temple in Devotional and Visionary Experience", Jewish Spirituality, Vol. I (supra cit.), pp. 32-59. 
El origen de esta tensión se ha buscado en el tiempo en el que tribus nómadas, que experimentaban a su Dios acompañándolas, llegaron a asentarse en Canaán, donde un campesinado agrícola las insertó en un medio cúltico totalmente nuevo, en el cual Dios aparece desde arriba, en un lugar sagrado. a través de un rilo sagrado, todo ello en el contexlo de celebración de los ciclos recurrentes de la naturalezath. La tensión entre la tradición de asentamiento y la tradición del Sinaí, arriba mencionadas, bien pudiera ser en el pentaleuco una retroyección de este conflicto llevada a cabo por los redactores. El hecho es que esta tensión no ha quedado suavizada en la vida de Israel, ni en las Escrituras hebreas, sencillamente porque los polos de las tensiones son, por su propia naturaleza, irreconciliables, a pesar del esfuerzo por comprender las exigencias de ambos ${ }^{47}$.

¿Cómo afecla esto a la cristología? Se puede presumir que los primeros seguidores judios de Jesús, aunque fuese de forma inconsciente, estaban influidos invariablemente por estos dos diferentes enfoques de la divinidad, expresados en los dos modelos de religiosidad que hemos visto. En todas las religiones no bíblicas, a las que Moltmann llama "religiones de epifanía", la Realidad Ultima "aparece" y "se revela a sí misma" en un lugar y en un tiempo que, por esa razón, queda santificado, o a través de un intermediario, un hombre-Dios (theos aner), que se convierte en persona sagrada. En lsrael tales apariciones visibles siempre quedan relativizadas por la palabra audible de la promesa, que apunta —más allá de liempos, lugares o personas sagradas - al futuro, en el cual se realiza la promesa. El tiempo y el mundo presentes quedan cuestionados por un pueblo que tiene el futuro como criterio de verdad. Se consideran, literalmente, como exiranjeros, en este tiempo y en este mundo. Son el pueblo del futuro, por lo menos idealmente, tal como lo exige la vocación y la misión que han recibido. De esta manera, la revelación de Yahweh no es una experiencia de unidad, entre el etemo presente de lo divino y nuestro mundo elímero y cambiante del aquí y ahora, que se consigue a través de ritos y oraciones, elevándonos, por así decirlo. Más bien, el encuentro con Yahweh queda configurado por un sentimiento de historia salvífica, que presupone necesariamente el recuerdo de la promesa, hecha en el pasado, y la esperanza de su cumplimiento en el futuro, convocándonos siempre hacia adelante.

La historia, según este modo de creer, queda definida esencialmente como un periodo de espera o de esperanza de cumplimiento, que se desborda siempre en una nueva promesa, que genera nuevas esperanzas. Así, en Canaán, cuando se cumplió la promesa, las tribus de Israel hicieron que esta concepción de historia transformara los festivales cíclicos de la religión cananea en otras tantas ocasiones de anamnesis de las promesas divinas, que generaban esperanza" ${ }^{44}$. Los

46. Moltmann, Theology of Hope, pp. 96-97, siguiendo a Víctor Maag, "Malkut Jhwh", Supplement to Vefus Tesfamentum, (Congress Volume, 1959) 1960, pp. 137-140.

47. Moltmann, op. cit.

48. Ibid., pp. 100 ss. 
festivales de la sociedad agraria de Candán, el de la cosecha, por ejemplo, fucron transformados en celebraciones conmemorativas de acontecimientos históricos, que se relacionaban con la experiencia del éxodo.

Las Escriluras cristianas continuaron esta Iradición hebrea en el modo en que resurrección y pentecostés fueron interprelados como los puntos culminanles de la pascua, que tuvo lugar en la cruz. Lo más específico de la fe judco-cristiana hace que lengamos que adherirnos a esla Iradición, según la cual el modelo del Dios-idelante es el énfasis principal de todo lo que lecmos en las Escriluras y de todo lo que proclamamos como nuestra fe, conscientes al mismo tiempo de que en el lexto sagrado la idea del Dios-arriba, salurada de religiosidad epifínica, está siempre latentc como una contra-presencia.

Desde esta perspectiva. parecería que en la tradición teológica que llevó a Calcedonia y prevaleció tras ese concilio. el o loges sarx egeneto del evangelista Juan y las afirmaciones "Yo soy" del Jesús joanneo, así como las relerencias hímnicas a la preexistencia de Cristo, en el cuerpo paulino y deuteropaulino, han quedado selladas con la dimensión óntica propia de la religión gricga. Los portadores de esta cristología no parecian ser conscientes de que quienes compusicron los himnos o se apropiaron de ellos lo hicieron porque querían decir algo acerca del fenómeno Jesús, y no porque quisieran especular acerca del ser Jivino con anterioridad a la historia".

Al aceplat estas palabras como verdaderas y válidas, no intento negar o ignorar la preexistencia de Cristo, sino simplemente avisar del peligro de que la cristología no esté basada en lo que nosorros, seres humanos, especulamos sobre la preexistencia de la palabra, en términos ónticos. Es pues razonable que en la línea de la tradición bíblica se deba poner el énfasis no tanto en cl Dios-arriba. que aparece en ligura humana, sino en el Dios-adelante, reconocido como Yahweh, el Dios fiel (el padre mitternal de Jesús), a través del movimienlo hacia adelante de la esperanza hacia la plenificación de su palabra de promesa en Jesús, el Cristo y como Jesús, el Cristo.

Si no aceptamos este cambio de paradigma, seguiremos sumidos en la confusión que genera el hábito de usar idioma óntico para designar el "fenómeno histórico de Jesús" como abajo y la "palabra eterna preexistente" como arriba, como se echa de ver claramente en el debate sobre el punto de partida de la cristología ${ }^{\text {(1) }}$. En este debate, en efecto, la palabra "histórico" y la frase "preexistente eternamente" poseen significados que se han introducido inconscientemente desde el modo de pensar de las religiones epifánicas. Esta confusión es, sin

49. Reginald H. Fuller y Pheme Perkins, Who is this Jesus? Goxpel Christology and Contemporary Faith, Fortress Press (Philadelphia, 1983, segunda edición, 1484), pp. 6-7.

50. Ibid., pp. 6-8. 
duda, consecuencia inevitable de la opción calcedoniana. Me temo que el debate sobre el enfoque funcional y ontológico de la crislologias" merece la misma crítica. Por esta razón, en la cristología de alianza que voy a desarrollar en la tercera parte, tales cuestiones simplemente no se plantean.

(Continuará en el próximo número.)

51. Ibld., pp. 8-10. 